\title{
UNIVERSIDADES CORPORATIVAS E O ENSINO PARA A SUSTENTABILIDADE
}

\author{
CORPORATE UNIVERSITY AND THE EDUCATION FOR SUSTAINABILITY
}

\author{
Texto convidado em Junho/2019 \\ Editora Científica convidada: Patricia Kanashiro \\ DOI I0.I3058/raep.20I9.v20n3.I636
}

\section{MONICA APARECIDA DE SORDI MARTÃO monicadesordi@uol.com.br JACQUES DEMAJOROVIC}

CENTRO UnIVERSITÁRIO FEI

\section{RESUMO}

Este artigo tem por objetivo verificar como universidades corporativas promovem a educação para a sustentabilidade de seus colaboradores e stakeholders externos de forma a integrar esta temática nas estratégias organizacionais. Para esta pesquisa qualitativa, a técnica de coleta de dados escolhida foi a entrevista semiestruturada, realizada com 16 Gestores de universidades corporativas sediadas no Estado de São Paulo. Os resultados apontam que, embora a sustentabilidade seja um componente estratégico presente no discurso organizacional, é praticamente inexistente modelos específicos e ações educacionais, relacionados propriamente com o tema. Destaca-se a falta de uma cultura para a sustentabilidade efetiva nas organizações e concentração do conhecimento relativo ao tema nos departamentos específicos de sustentabilidade, que contribui para um aprendizado fragmentado e pontual, dificultando a apropriação deste conhecimento nas demais unidades organizacionais e a incorporação da temática na estratégia das organizações pesquisadas. O principal desafio encontrado se refere à construção de diálogo colaborativo entre as universidades corporativas, áreas de sustentabilidade e demais setores organizacionais que facilite um processo formativo efetivo nas organizações, conciliando objetivos econômicos, ambientais e sociais.

Palavras-chave: Universidade Corporativa, Educação, Sustentabilidade.

\begin{abstract}
The purpose of this paper to verify how corporate universities promote education for sustainability among its employees and external stakeholders in order to integrate this theme into the organization strategies. For this qualitative research, the data collection technique chosen was the semi-structured interview, performed with 16 corporate universities managers based in the state of São Paulo. The results indicate that although sustainability is a strategic component, present in the organizational discourse, there are practically nonexistent specific models and educational actions related to the theme. The barriers are the following: the lack of a sustainability culture in the organizations and the concentration of the knowledge of this theme in specific sustainability departments. By assigning sustainability education to these departments, learning ends up being fragmented and punctual, hindering the appropriation of this knowledge in other organizational units and the incorporation of this theme into the strategy of organizations researched. Thus, the main challenge founded is the construction of collaborative dialogue between corporate universities, sustainability areas and other organizational departments that foster an effective learning process in organizations reconciling economic, environmental and social objectives.
\end{abstract}

Key words: Corporate University, Education, Sustainability 


\section{INTRODUÇÃO}

Universidade Corporativa (UC) e Sustentabilidade são temas contemporâneos nas organizações, intensificando-se o interesse acadêmico pelos mesmos a partir dos anos 2000. Ambos entendidos como elementos importantes das estratégias organizacionais podem ser considerados como fontes de vantagem competitiva. Entretanto, apesar da contemporaneidade, estes temas parecem andar paralelamente no meio organizacional existindo uma lacuna na literatura no que se refere ao papel e atuação da UC com relação à educação para sustentabilidade nas organizações (BRUNSTEIN; RODRIGUES, 2014; ANTONELLI, CAPPIELLO; PEDRINI, 2013; PARENTE; FISCHER, 2014; ENGERT et al., 2015; ALVARES; SOUZA, 2016).

Para que as organizações permaneçam competitivas, precisam entender as mudanças no ambiente e desenvolver de maneira rápida e eficaz respostas adequadas para lidar com os novos desafios impostos pelos mercados e tecnologias. Para muitos autores, esses desafios podem e devem ser enfrentados recorrendo-se a educação continuada dos colaboradores das organizações, sendo a UC um ator relevante neste processo. (CARBONE, 2013; ANTONELLI CAPPIELLO; PEDRINI, 2013; SENGUR; ACAR, 2014; RYAN et al., 2015; RHEAUME; GARDONI, 2015). Renaud-Coulon (2008) defende a integração de novas e complexas responsabilidades para a UC, relacionadas às discussões de temas mais atuais, ligados aos avanços sociais, tais como: responsabilidade socioambiental, diversidade cultural, ética e cidadania, entre outras. Na mesma direção, Tsipes et al. (2016) argumentam que em cenário de novas áreas de conhecimento, técnicas e padrões profissionais, a UC ocupa uma posição central para preparar a organização para se alinhar ao desenvolvimento sustentável e aos interesses dos stakeholders internos e externos.

Com relação à sustentabilidade, embora discutida desde a década de 70, foi a partir do final da década de 1990 que se integrou ao cotidiano das organizações com mais evidência, devido principalmente ao avanço da legislação ambiental, às pressões sociais e ao reconhecimento de que a integração da preocupação ambiental e social aos negócios, contribui para 
o desenvolvimento de vantagem competitiva nas organizações (BELINKY, 2016; HART; MILSTEIN, 2003). No entanto, diversas pesquisas mostram grande resistência de empresas em relação a integração efetiva nos processos decisórios das variáveis ambientais e sociais, visto que ainda são muitas vezes consideradas um fardo financeiro e não oportunidade de negócio ou diferencial competitivo (WILSON et al., 2006; HUBBARD, 2009; PORTER; KRAMER, 2011; COLEMAN, 2013; ENGERT et al., 2015; BLAKE, 2016).

Para que a sustentabilidade esteja presente nas discussões das estratégias empresariais, é preciso transcender os modelos atuais de negócios e desenvolver uma nova forma de pensar e planejar o futuro. Isso ocorrerá por meio da educação corporativa continuada, da aprendizagem individual e organizacional para a sustentabilidade, de processos inovadores de aprendizagem e do envolvimento de todos os níveis hierárquicos presentes nas organizações (DEMAJOROVIC, 2003; AREVALO et al., 2011; BRUNSTEIN et al., 2012; COLEMAN, 2013).

Nesse contexto, propõe-se a seguinte pergunta de pesquisa: como as UCs contribuem para o processo de educação para sustentabilidade nas organizações de forma a atender as estratégias organizacionais? Para responder esta pergunta definiu-se como objetivo: verificar como Universidades Corporativas promovem a educação para a sustentabilidade nos seus diversos níveis organizacionais, tanto para colaboradores como para stakeholders externos, visando o cumprimento das estratégias organizacionais relacionadas à sustentabilidade. Para tanto, optou-se por um trabalho de natureza qualitativa, a partir de entrevistas em profundidade com 16 gestores de UCs sediadas em São Paulo. 


\section{CONCEITUANDO UNIVERSIDADE CORPORATIVA}

O termo UC foi definido pesquisadora americana Jeanne C. Meister, como "um guarda-chuva estratégico para desenvolver e educar funcionários, clientes, fornecedores e comunidade, a fim de cumprir as estratégias empresariais da organização" (MEISTER, 1999, p.29). Uma "UC é um nome genérico dado a estruturas educacionais presentes em organizações públicas e privadas, comerciais e não comerciais, para ajudar a implementar, por meio da educação, estratégias da organização em termos humanos, econômicos, financeiros, tecnológicos, sociais e ambientais", caracterizando-se como importante ferramenta que "forja a identidade corporativa e a alma da corporação" (RENAUD-COULON, 2008, p.23). Margherita e Secundo (2009) e Allen (2010) enfatizam a abrangência do campo de atuação da UC, promovendo até mesmo processos globais e atendimento a múltiplos objetivos, múltiplos currículos, múltiplas metodologias de aprendizagem, múltiplas tecnologias para cumprir seus múltiplos papeis. No entanto há quem defenda que a UC é uma evolução dos conhecidos departamentos de Treinamento e Desenvolvimento (T\&D) das organizações, principalmente nas organizações que passaram a considerar o conhecimento e a capacidade de aprendizagem de seus colaboradores como principal fonte de vantagem competitiva (MEISTER, 1999; ALPERSTEDT, 2001; EBOLI, 2004; SENGE, 2004).

A educação nas organizações passou a valorizar o desenvolvimento da capacidade do indivíduo em aprender, em pensar, em articular, em participar, em buscar novas soluções e não apenas na transferência de conhecimento (PRINCE; BEAVER, 2001; VERGARA; RAMOS, 2002; EBOLI, 2004; CONTE et al., 2011, WESSENLINK et al., 2015), chegando ao estágio mais evoluído, até o presente momento, onde a UC relaciona a capacidade de catalisar mudanças institucionais, envolvendo diretamente a alta administração das organizações (CASTRO E EBOLI, 2013). Neste estágio, a UC torna-se parceira do planejamento estratégico da organização, atuando como agente de gestão da cultura corporativa e desenvolvendo competências estratégicas que visam garantir o sucesso da organização. Embora mui- 
tos autores atribuam uma importância elevada à UC, outros afirmam que não passa de um truque das organizações, a fim de se autopromoverem no meio organizacional (WALTON, 1999), causando a banalização do saber, sem promover nos colaboradores a conscientização de seus papeis como cidadãos na sociedade (SILVA, 2005).

De forma mais branda, Prince e Beaver, (2001) e Tarapanoff (2004), concordam que o termo UC tem um valor simbólico e até mesmo um apelo de marketing que objetiva melhorar o posicionamento da aprendizagem dentro das organizações, apontam que o termo Universidade não tem a intenção de tentar concorrer ou substituir a relevância e a formação proporcionadas pelas Universidades Tradicionais (UT), porém ter o nome "Universidade", sem ter as características, o modus operandi e a legislação de uma UT, pode trazer muitas vantagens para as UCs como: o status do nome, remetendo a uma ferramenta de gestão de alto nível; ter autonomia de desenhar os cursos conforme sua necessidade; poder determinar o tempo de duração que julgar adequado; ter a liberdade de contratar o profissional que quiser como docente; e facilidade para conduzir a aprendizagem, o que favorece o alinhamento das necessidades de aprendizagem com as necessidades estratégicas determinadas pela organização.

O objetivo mais comum de uma UC é a promoção do desenvolvimento de seus principais stakeholders, por meio da educação continuada, a fim de cumprir as estratégias organizacionais e gerar vantagem competitiva e sua implementação e modo operacional difere entre as organizações, uma vez que cada UC é influenciada pelo tamanho da organização, pela disponibilidade financeira e, principalmente, pela a relevância atribuída a ela pela alta direção. Portanto, não convém estabelecer o mesmo modelo de implantação e atuação para todas as UCs (BRANCO, 2006; MCATEER; PINO, 2011). Entre as características principais dos programas de educação promovidos pelas UCs, destacam-se o formato de educação continuada, os currículos flexíveis, as metodologias diferenciadas, as parcerias com instituições terceiras (universidades tradicionais, consultorias e centros especializados) e a diversidade do público-alvo, podendo ser colaboradores diretos, clientes, fornecedores e comunidade em ge- 
ral (MEISTER, 1999; VERGARA; RAMOS, 2002; EBOLI, 2004; ALLEN, 2007; CONTE et al., 2011).

Diante de tamanha diversidade de definições e de amplitude do que possa ser considerado uma UC, Reis et al. (2010) inferem que UC não se define pelo conjunto de ações de treinamento e desenvolvimento que as organizações oferecem para seus colaboradores e parceiros de sua cadeia de valor, mas sim pelo fato de contribuir para um objetivo maior que é integrar todas as ações educacionais da organização, contribuindo para a eficácia da estratégia organizacional (ANTONELLI et al., 2013; BAPORIKAR, 2014; RHÉAUME; GARDONI, 2015). Para alcançar este objetivo, a literatura foca em 3 elementos centrais no debate atual relacionados à UC: as estratégias de aprendizagens; os recursos tecnológicos e a formação de parcerias.

\section{Estratégias de Aprendizagem}

Diversas estratégias de aprendizagem são empregadas pelas UCs. Muitas delas são utilizadas desde os primórdios do T\&D. Outras surgiram conforme a evolução da aprendizagem organizacional (BAPORIKAR, 2014; MOSCARDINI; KLEIN, 2015; CARMELLO, 2015). Pode-se citar como exemplos: autoinstrução, aulas expositivas, debates, aprendizagem baseada em problemas, estudos de caso, dramatização, workshops, benchmark, job rotation, participação em projetos, jogos, comunidades de prática, coaching, mentoring (MOSCARDINI; KLEIN, 2015). Outras metodologias inovadoras para a promoção da aprendizagem e adaptação às mudanças organizacionais e globais são listadas por Carmello (2015): design thinking, modelo 70/20/10, aprendizagem singular e/ou personalizada (trilhas de desenvolvimento), aprendizado híbrido e aprendizado baseado em projetos. Estas estratégias ou metodologias de aprendizagem estão disponíveis para as UCs, sendo que o uso e escolhas delas devem estar relacionadas com as necessidades de desenvolvimento de conhecimentos importantes para o alcance dos objetivos e estratégia organizacional. A importância da exploração e desenvolvimento de novos conhecimentos é reconhecida como um direcionamento para a inovação. De acordo com Rheaume e 
Gardoni (2015), a UC pode se tornar um "verdadeiro centro de inovação", por meio de parcerias estratégicas, facilitando e por vezes, promovendo as mudanças organizacionais necessárias para a inovação.

\section{Recursos Tecnológicos}

A tecnologia da informação é reconhecida como uma importante aliada das UCs. A maioria das organizações investem muito em e-learning como forma de promoção da educação e do aprendizado, pois constatam as vantagens que esta metodologia traz, como custo mais baixo em relação a aprendizagem presencial, flexibilidade para rápida atualização e personalização de conteúdo, gestão dos programas em nível mundial e o avanço constante de novas ferramentas de redes sociais para a disseminação e discussões de conteúdo. (EBOLI, 1999; ALLEN, 2002; HOMAN; MACPHERSON, 2005), além da capacidade de promover uma mudança mental nos funcionários, ou seja, dar autonomia para que aprendam sozinhos, sem a dependência de sala de aula e professor (ABEL; LI, 2012). Embora seja indiscutível a importância que a tecnologia da informação e as metodologias e-learning passaram a ter para as UCs, pesquisas começaram a apontar taxa de evasão dos participantes de programas e-learning superior aos programas presenciais (ZERBINI et al., 2006) evidenciando que sua efetividade não é totalmente garantida. Considerar alternativas de metodologias de aprendizagem. além do e-learning, como a tradicional capacitação presencial e simulações com casos reais de forma combinada, é fundamental para o aumento da efetividade da aprendizagem em todos os níveis das organizações (STACEY; GERBIC, 2009; ALLEN, 2010; ABEL; LI, 2012; CASTRO; EBOLI, 2013).

\section{Formação de Parcerias}

As UCs não conseguem suprir suas demandas de aprendizado totalmente, sendo necessário o desenvolvimento e gerenciamento de parcerias, interna (outros departamentos) e externas (UTs, consultores e fornecedores) (ABEL e LI, 2012). Em relação as UTs, as parcerias visam promover programas customizados e personalizados, com objetivo de desenvolver conteúdos pertinentes ao trabalho, podendo inclusive ter o certificado de graduação 
e MBA's reconhecidos legalmente. Programas de mestrado e doutorado também podem ser incluídos com o objetivo de formar profissionais focados em pesquisas e processos de inovação (RYAN, 2009). Baporikar (2014) destaca a importância destas parcerias, uma vez que as UTs podem prover às UCs estruturas didáticas adequadas, professores capacitados para o desenvolvimento e atualização de modelos, e metodologias modernas, tanto de gestão como de aspectos técnicos. Por sua vez, as UTs percebem neste relacionamento com as UCs, a possibilidade de ter uma fonte de recursos financeiros. 


\section{A EFETIVIDADE DA UNIVERSIDADE CORPORATIVA}

As muitas definições de UC, a falta de um modelo específico a ser seguido fielmente por todas as organizações e de uma visão clara de como uma UC contribui efetivamente para a aprendizagem, inovação e estratégia organizacional (BAPORIKAR, 2014), leva as organizações a formatarem suas UCs de acordo com sua necessidade e disponibilidade. Abel e Li (2012) realizaram uma pesquisa com 210 UCs da América do Norte, objetivando obter evidências empíricas para explorar e avançar na compreensão do fenômeno da UC. Os resultados apontaram que as UCs existem em uma grande variedade de organizações, com diferentes estruturas e a maioria são financiadas exclusivamente pelas próprias organizações; que, quanto maior a dependência da organização de seu capital intelectual para mantê-la e/ou aumentar sua competitividade global, (por ex. organizações de TI), maior a ênfase atribuída às UCs, sendo consideradas importantes parceiras para a promoção e desenvolvimento intelectual da organização.

Como tendências para a UC, Baporikar (2014) destaca: maior uso de terceirização da aprendizagem, profissionalização do papel de Chief Learning Officer (CLO) e inovação na gestão do negócio de aprendizagem. Já como desafios, a autora destaca cultivar e combinar experiências diversificadas e especializadas que se traduzam em novos conhecimentos para a promoção da inovação; tornarem-se economicamente produtivas, por meio da rápida e contextualizada aplicação dos conhecimentos gerados, antes que se tornem obsoletos; e acompanhamento e utilização das novas TIC (Tecnologias de Informação e Comunicação), que fornecem meios para apoio de comunidades virtuais e formatos pedagogicamente mais sofisticados de e-learning. Ryan et al. (2015) também discorrem sobre as tendências para UC, como: necessidade das organizações responderem com mais agilidade às turbulências externas; diminuição das estruturas físicas, devido ao surgimento e barateamento de novas tecnologias de informação; maior utilização de serviços terceirizados; atração e retenção de talentos para compor a força de trabalho; e personalização do plano de desenvolvimento individual dos colaboradores. 
O principal desafio de uma UC, segundo Kolo et al. (2013), é adaptar continuamente seus modelos de atuação e de estruturação, a fim de encontrar soluções e novas estratégias para um mercado mundial cada vez mais volátil e imprevisível, além de fomentar a aprendizagem constante ao longo da vida dos colaboradores.

No Brasil, UC é definida como "um sistema de desenvolvimento de pessoas pautado pela gestão de pessoas por competências"(EBOLI, 2004, p.48), com a missão de formar e desenvolver talentos na gestão dos negócios, promovendo assim a gestão do conhecimento organizacional (geração, assimilação, difusão e aplicação), através de um processo de aprendizagem ativa e contínua. Em pesquisa com UC brasileiras em 2009, Eboli (2010) apontou como tendência para os principais objetivos das UCs nos próximos cinco anos: o desenvolvimento de lideranças (78\%); a aprendizagem colaborativa (64\%); a avaliação e mensuração de resultados da UC (57\%); e o desenvolvimento e aperfeiçoamento do ensino a distância (54\%). E como desafios: atuação estratégica (80\%); avaliação e mensuração de resultados (71\%) e promoção do autodesenvolvimento dos colaboradores (42\%).

As pesquisas desenvolvidas no Brasil em relação às UCs continuam a abordar prioritariamente as características das mesmas, com relação aos pressupostos estabelecidos no surgimento da conceituação feita por Meister (1999) e por Eboli (2004). Poucas pesquisas, no entanto, procuram focar temas específicos desenvolvidos nestas UCs, como: estratégia organizacional; e escolhas e definição de conteúdo dos temas e como são disseminados e transformados em ações práticas.

A falta de um entendimento mais apurado da efetividade das UCs pode estar contribuindo para um cenário de incertezas sobre seu futuro nas organizações. Alagaraja e Li (2015) identificaram que a relevância das UCs nas organizações começou a declinar. Primeiro, devido à forte crise financeira global de 2008, que ainda tem efeitos negativos sobre a economia mundial, o que acarreta limitações orçamentarias, bem como redução de investimentos. Segundo, devido a mudança de foco de associações, consultores e organizações profissionais relacionadas ao RH, voltando suas atenções para a gestão de talentos. E terceiro, devido a pressão sociocul- 
tural das UTs, que questionam a legitimidade das UCs no que se refere ao desenvolvimento de tecnologias de ponta e inovações.

Apesar destas incertezas, para que as UCs mantenham sua relevância no processo de capacitação de seus colaboradores e contribuam para a efetividade das estratégias organizacionais, é necessário incorporar novos conteúdos sintonizados com as mudanças sociais. Nessa direção, Renaud-Coulon (2008) destaca novas responsabilidades para as UCs, relacionadas com os debates mais atuais que passaram a integrar as discussões nas organizações, como globalização, diversidade e responsabilidade socioambiental. 


\section{EDUCAÇÃO CORPORATIVA PARA SUSTENTABILIDADE}

Transcender os modelos atuais de negócios se torna imperativo para a incorporação da Sustentabilidade nas organizações e para que isso ocorra, Arevalo et al. (2011) defendem a necessidade do desenvolvimento de novos modelos de negócios que incorporem variáveis como intenções estratégicas diferenciadas e traços culturais diversos, exigindo assim novas competências em todos os níveis hierárquicos de uma organização. Para o autor, este processo depende de uma nova forma de educação que passa, necessariamente, também pela aprendizagem nas organizações que promova ações comprometidas com a Sustentabilidade.

Num estudo de oito casos de organizações, de diversas regiões do mundo, que incorporaram Sustentabilidade na sua cultura e nos seus modelos de negócios, Arevalo et al. (2011) identificaram que o processo de mudança acontece de forma lenta e gradual, pois necessita de uma educação que promova a construção de um sentido individual da Sustentabilidade que gere mudanças comportamentais individuais. Estas mudanças, por sua vez, tendem a promover a construção do sentido coletivo da Sustentabilidade, influenciando assim nas decisões e nas ações organizacionais. Esses processos, quando bem conduzidos, geram também mudanças na identidade organizacional e, consequente, no comportamento e cultura organizacional. Para que essa cultura da Sustentabilidade seja legítima, tem que ser disseminada por todos os níveis hierárquicos e traduzida em ações efetivas (HART, 2006; GAO; BANSAL, 2013; AHERN, 2015; BLAKE, 2016). Oncica-Sanislav e Candea (2010) defendem que, para as lideranças estabelecerem objetivos de longo prazo que privilegiem aspectos socioambientais, além dos econômicos, é necessário que a cultura da Sustentabilidade esteja presente, disseminada e validada por toda a organização. Caso contrário, resistências quanto à incorporação da sustentabilidade podem impedir sua inserção na cultura organizacional. Para Coleman (2013) e Blake (2016), resistências quanto ao tema ainda existem em todos os níveis hierárquicos das organizações, principalmente nos níveis estratégicos, devido ao modelo de gestão do- 
minante, que ainda valoriza o fator econômico em detrimento aos fatores socioambientais.

Tradicionalmente nas organizações, as funções de disseminação de cultura, desenvolvimento de pessoas, aprendizagem e mudança comportamental estão sob a responsabilidade da área de Recursos Humanos (RH), mais especificamente no T\&D. Para Crews (2010) é necessário o desenvolvimento de uma agenda que privilegie a implantação da Sustentabilidade nas organizações, por meio de novos talentos e principalmente, com o desenvolvimento de programas que viabilizem a incorporação e práticas da Sustentabilidade.

Parente e Fischer (2014) também destacam que o desafio das organizações em relação a promoção da sustentabilidade está diretamente ligado a mobilização e sensibilização das pessoas, ou seja, não se pode abordar a sustentabilidade nas organizações sem que se pense nas pessoas. Assim, acreditam que a área de RH das organizações passa a ser responsável por boa parte da política de sustentabilidade. Porém, analisando a literatura nacional e internacional sobre o tema, investigando publicações entre 2001 e 2011, os autores concluíram que ainda não existem pesquisas que identifiquem modelos de atuação específicos de práticas de RH para o desenvolvimento da sustentabilidade. Já a pesquisa de Tsipes et al. (2016), que também enfatiza a importância do RH, alerta que sem real envolvimento da alta liderança, a incorporação da sustentabilidade na cultura da empresa se torna um objetivo bastante difícil de ser alcançado.

A aprendizagem das competências para a sustentabilidade se dá por meio de um processo contínuo, coletivo e contextual, dificil de ser captado para ser posteriormente ensinado (WESSENLINK et al., 2015). O autodesenvolvimento se torna peça-chave para as organizações, as discussões e feedbacks sobre o tema devem ser constantes. Brusntein e Rodrigues (2014) propõem que este desenvolvimento de conhecimento e competências sobre sustentabilidade ocorra por meio de diálogos reflexivos. Algumas experiências relevantes são realizadas com base no uso da aprendizagem por meio de conscientização. Programas de desenvolvimento de liderança, realizados por meio de missões internacionais de aprendizado de serviços, 
são citados por Roome e Louche (2011) e Ragusa (2011). Segundo Pless et al. (2012), em alguns destes programas os executivos e gerentes são enviados a países em desenvolvimento, para trabalhar em organizações locais e assim desenvolver a liderança global, o conhecimento real dos dilemas enfrentados por sociedades carentes, reconhecer e lidar com a escassez de recursos naturais e infraestrutura mínima, e assim, conscientizar estes para a necessidade de incorporar a Sustentabilidade nas estratégias organizacionais, visando o desenvolvimento sustentável mundial.

Além de fatores internos às organizações que favoreçam o desenvolvimento de competências em sustentabilidade, a pesquisa de Antonelli et al. (2013) mostra a importância de fatores externos às empresas, na forma de atuação de suas UCs. Em seu trabalho com seis UCs de indústrias do serviço público no ramo de energia, os autores destacam como principal fator motivador para que essas UCs incorporassem a sustentabilidade em seus currículos, foi o crescimento dos princípios da sustentabilidade, do entendimento e cumprimento das políticas ambientais estabelecidas na Agenda de Lisboa e também a iniciativa "Uma Europa eficiente em termos de recursos", formulada pela Estratégia Europa 2020, que valoriza conquistas relacionadas à sustentabilidade ambiental. Destaca-se ainda que essas UCs organizam e promovem o conhecimento entre vários stakeholders, como outras UTs, outras indústrias e o próprio Governo.

Ainda que se considere estas contribuições teóricas, verifica-se ainda um limitado número de trabalhos que analisem como as UC estão incorporando conteúdos e práticas em sustentabilidade, além de investigar os desafios enfrentados por estas unidades neste processo. Brunstein e Rodrigues (2014) relatam a carência de trabalhos relativos ao desafio de gestores em transformar o discurso de conceitos e competências relativas à Sustentabilidade, em ações cotidianas práticas, e as críticas apontando a dissonância entre o discurso proferido e as ações tomadas são frequentes. A seguir detalha-se os procedimentos metodológicos adotados para o trabalho de campo realizado. 


\section{PROCEDIMENTO METODOLÓGICO}

Esta pesquisa é de natureza qualitativa e pretendeu discutir o fenômeno estudado a partir da visão de mundo das pessoas diretamente envolvidas com a temática (MERRIAM, 1998). A escolha por investigar a relação entre UC e educação para sustentabilidade, partiu do pressuposto de que estes dois temas devem ter muitas ligações, pois ambos estão relacionados ao cumprimento das estratégias organizacionais e são considerados fontes de vantagem competitiva.

Definiu-se como objeto de pesquisa 16 Universidades Corporativas, que atuam no Brasil, com sede em São Paulo, pertencentes tanto a organizações nacionais como internacionais, de diferentes setores de atuação energia, logística, serviços especializados (consultorias), serviços automotivos, montadora, papel e celulose, alimentação, segurança patrimonial, químico, saúde animal e serviços financeiros. Dois fatores influenciaram na escolha das UCs participantes. O primeiro considerou a existência da sustentabilidade como fator relevante para a organização a qual a UC pertence, seja por práticas ou pela cultura organizacional divulgadas, constatadas pela busca nos websites oficiais das organizações. O segundo fator significativo para a escolha foi o acesso a essas UCs. De 27 UCs contactadas, obteve-se permissão de 16 delas. Os motivos alegados por onze UC, para a não participação, foram os mais diversos, como não autorização da diretoria, falta de tempo para atendimento, falta de interesse em pesquisas acadêmicas e quatro UC nem responderam ao convite. Das que concordaram em participar, a maioria foi possível devido ao contato profissional anterior dos autores com pessoas responsáveis pelas próprias UCs ou mesmo responsáveis pelas áreas de RH e por meio de algumas indicações de professores e outros profissionais.

Em relação à coleta de dados, utilizou-se duas técnicas. Primeiramente realizou-se uma análise documental, via websites das organizações, a fim de verificar a relevância dada à sustentabilidade, a partir da inclusão da temática na missão, visão, valores, cultura ou mesmo a existência de algum item específico destacado no website, sobre sustenta- 
bilidade. Estes dados auxiliaram nas entrevistas com os gestores, feitas posteriormente.

A segunda técnica foi a entrevista semiestruturada com os principais gestores destas UCs. Ressalta-se que o título do cargo e sua posição hierárquica assumem nomenclaturas diferentes nas UC. O quadro 1 mostra o perfil das empresas e dos entrevistados.

Todas as entrevistas foram transcritas para posterior análise de seus conteúdos (BARDIN, 2004), com base nas categorias (Quadro 2) definidas a partir da revisão da literatura. 


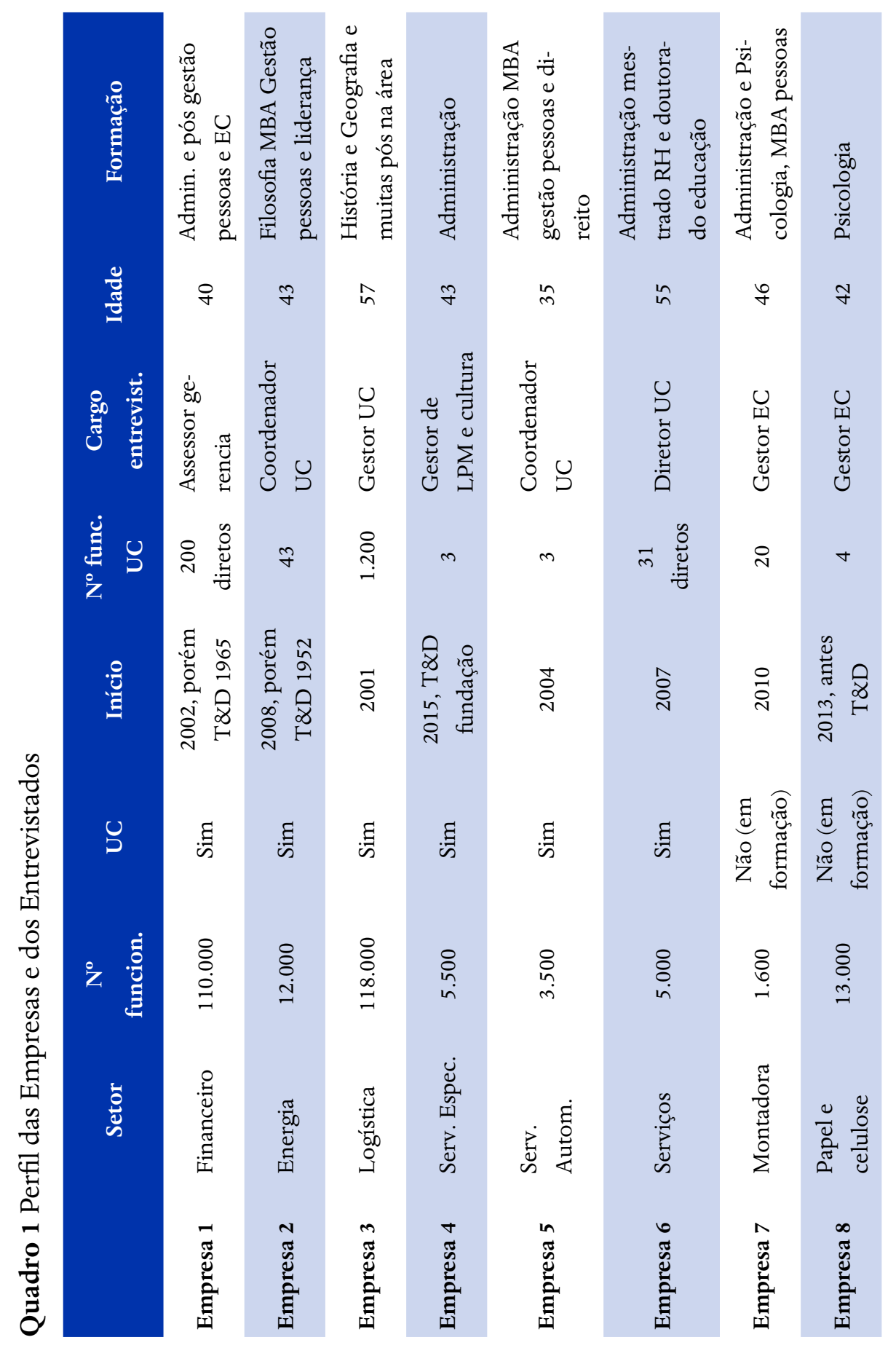




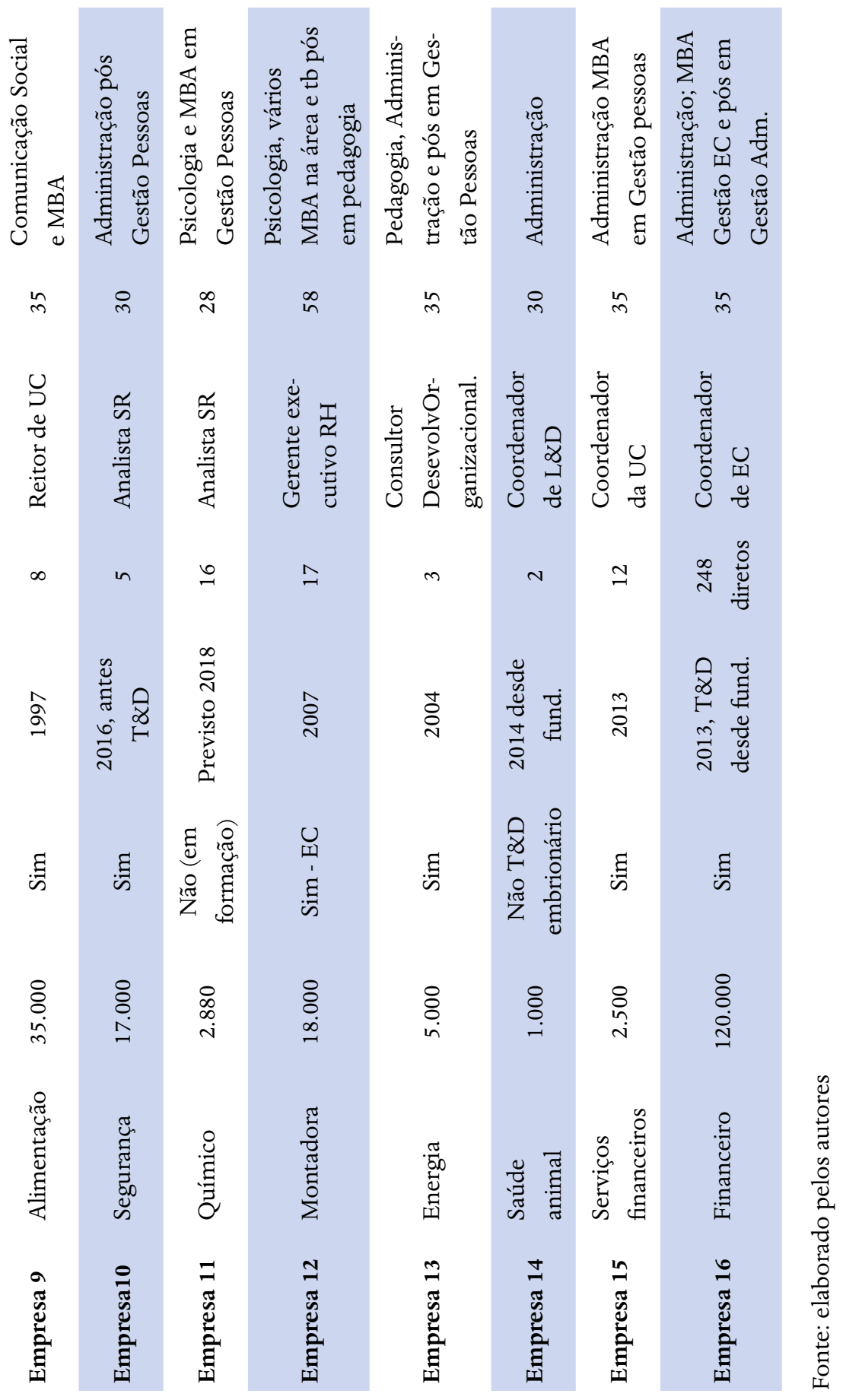


Quadro 2 Categorias Analíticas construídas a partir da Revisão da Literatura

\begin{tabular}{|c|c|c|}
\hline \multirow{3}{*}{$\begin{array}{l}\text { Cultura / mis- } \\
\text { são / valores / } \\
\text { estratégia orga- } \\
\text { nizacional }\end{array}$} & $\begin{array}{l}\text { Sustentabilidade } \\
\text { econômica }\end{array}$ & \multirow{3}{*}{$\begin{array}{l}\text { Meister (1999); Eboli (1999); Veiga } \\
\text { (2010); Claro O. e Claro D. (2014); } \\
\text { Parente e Fischer (2014); Engert et } \\
\text { al. (2015); Blake (2016); Tsipes et } \\
\text { al. (2016) }\end{array}$} \\
\hline & Sustentabilidade social & \\
\hline & $\begin{array}{l}\text { Sustentabilidade } \\
\text { ambiental }\end{array}$ & \\
\hline \multirow{3}{*}{ 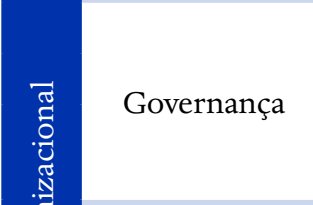 } & Alta administração & \multirow{3}{*}{$\begin{array}{l}\text { Pless et al. (2012); Parente e } \\
\text { Fischer (2014); Castro e Eboli } \\
\text { (2013); Baporikar (2014); Alagara } \\
\text { e Li (2015) }\end{array}$} \\
\hline & Recursos Humanos & \\
\hline & Independente & \\
\hline \multirow{3}{*}{$\begin{array}{l}\text { Abrangência / } \\
\text { relevância }\end{array}$} & $\begin{array}{l}\text { Educação/ desenvolvi- } \\
\text { mento/treinamento }\end{array}$ & \multirow{3}{*}{$\begin{array}{l}\text { Wilson, Lenssen e Hind (2006); } \\
\text { Allen (2010); Jothi (2010); Porter } \\
\text { e Kramer (2011); Abel e Li (2012); } \\
\text { Carbone (2013); Baporikar (2014); } \\
\text { Ryan et al. (2015); Dlouhá (2013); } \\
\text { Rheaume e Gardoni (2015) }\end{array}$} \\
\hline & $\begin{array}{l}\text { Apoio à estratégia } \\
\text { organizacional }\end{array}$ & \\
\hline & $\begin{array}{l}\text { Centro de pesquisa e } \\
\text { desenvolvimento }\end{array}$ & \\
\hline \multirow{3}{*}{ Estrutura } & Física (\%) & \multirow{3}{*}{$\begin{array}{l}\text { Meister (1999); Eboli (1999); } \\
\text { Homan e MacPherson (2005); } \\
\text { Abel e Li (2012); Baporikar (2014) }\end{array}$} \\
\hline & E-learning $(\%)$ & \\
\hline & Mista $(\%)$ & \\
\hline \multirow{2}{*}{ Financiamento } & Dependência organização & \multirow{2}{*}{$\begin{array}{l}\text { Meister (1999); Eboli (1999); } \\
\text { Branco (2006); Baporikar (2014) }\end{array}$} \\
\hline & Autossuficiente & \\
\hline \multirow{3}{*}{$\begin{array}{l}\frac{8}{\tilde{\sigma}} \\
\frac{\pi}{0}\end{array}$ Público-alvo } & Interno (colaboradores) & \multirow{3}{*}{$\begin{array}{l}\text { Meister (1999); Eboli (1999, } \\
\text { 2004a); Prince e Beaver (2001); } \\
\text { Kraemer (2004); Ragusa (2011); } \\
\text { Gao e Bansal (2013) }\end{array}$} \\
\hline & $\begin{array}{l}\text { Cadeia produtiva } \\
\text { (fornecedores e clientes) }\end{array}$ & \\
\hline & $\begin{array}{l}\text { Comunidade / sociedade } \\
\text { em geral }\end{array}$ & \\
\hline \multirow{3}{*}{ Currículo } & $\begin{array}{l}\text { Desenvolvimento } \\
\text { competências pessoais }\end{array}$ & \multirow{3}{*}{$\begin{array}{l}\text { Wilson, Lenssen e Hind (2006); } \\
\text { Renaud-Coulon (2008); Edwards } \\
\text { (2009); Claro (2008); Brunstein et } \\
\text { al. (2012) }\end{array}$} \\
\hline & $\begin{array}{l}\text { Conhecimentos aspectos } \\
\text { sustentabilidade }\end{array}$ & \\
\hline & Desafios para inovação & \\
\hline \multirow{3}{*}{$\begin{array}{l}\text { Envolvimento } \\
\text { organizacional }\end{array}$} & Boarding (alta liderança) & \multirow{3}{*}{$\begin{array}{l}\text { Wilson; Lenssen; Hind (2006); } \\
\text { Claro (2008); Crews (2010); } \\
\text { Brunstein et al. (2012); Dlouhá et } \\
\text { al. (2013); }\end{array}$} \\
\hline & Gerencia (média liderança) & \\
\hline & $\begin{array}{l}\text { Todos níveis } \\
\text { organizacionais }\end{array}$ & \\
\hline
\end{tabular}




\begin{tabular}{|c|c|c|}
\hline \multirow{3}{*}{ Parcerias } & Universidades tradicionais & \multirow{3}{*}{$\begin{array}{l}\text { Eboli (2004); Allen (2007); Mar- } \\
\text { gherita e Secundo (2009); Abel e Li } \\
\text { (2012); Castro e Eboli (2013); Ala- } \\
\text { garaja e Li (2015); Ryan et al. (2015) }\end{array}$} \\
\hline & $\begin{array}{l}\text { Consultorias } \\
\text { especializadas }\end{array}$ & \\
\hline & Institutos especializados & \\
\hline \multirow{3}{*}{ 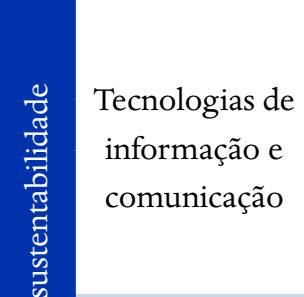 } & $\begin{array}{l}\text { e-learning (somente } \\
\text { virtual) }\end{array}$ & \multirow{3}{*}{$\begin{array}{l}\text { Homan e MacPherson (2005); } \\
\text { Stacey e Gerbic (2009); Balkanska; } \\
\text { Georgiev; Popova (2010); Creva- } \\
\text { ni; Lindgren; Packendorff (2010); } \\
\text { Stacey e Gerbic (2009); Abel e Li } \\
\text { (2012); Moscardini e Klein (2015) }\end{array}$} \\
\hline & Aprendizagem mista & \\
\hline & $\begin{array}{l}\text { Aprendizagem com } \\
\text { mobilidade }\end{array}$ & \\
\hline \multirow[b]{2}{*}{$\begin{array}{l}\text { Metodologias } \\
\text { de } \\
\text { aprendizagem }\end{array}$} & $\begin{array}{l}\text { Formais (aula expositiva, } \\
\text { aprendizagem individua- } \\
\text { lizada, seminários, estudo } \\
\text { de casos, grupos de estu- } \\
\text { do, workshop) }\end{array}$ & $\begin{array}{l}\text { Allen (2002); MacGregor e Semler } \\
\text { (2012); Balkanska, Georgiev; Po- } \\
\text { pova (2010); Moscardini e Klein } \\
\text { (2015); Carmello (2015) }\end{array}$ \\
\hline & $\begin{array}{l}\text { Experienciais (projetos } \\
\text { baseados em problemas } \\
\text { reais, benchmarking, } \\
\text { jogos ou gamificação, } \\
\text { comunidades de prática, } \\
\text { aprendizado no trabalho, } \\
\text { experiências em regiões e } \\
\text { comunidades diferentes }\end{array}$ & $\begin{array}{l}\text { Illeris (2003); MacGregor e Semler } \\
\text { (2012); Gao e Bansal (2013); Cea- } \\
\text { sar e Page (2013); Canto de Loura } \\
\text { (2014); Moscardini e Klein (2015); } \\
\text { Carmello (2015) }\end{array}$ \\
\hline \multirow{4}{*}{ Barreiras } & $\begin{array}{l}\text { Resistência (funcionários } \\
\text { / alta administração) }\end{array}$ & \multirow{4}{*}{$\begin{array}{l}\text { Hart (2006); Claro (2008); } \\
\text { Oncica-Sanislav e Candea (2010); } \\
\text { Albetin e Brauer (2012); Coleman } \\
\text { (2013); Blake (2016) }\end{array}$} \\
\hline & $\begin{array}{l}\text { Dificuldade mudança } \\
\text { cultural }\end{array}$ & \\
\hline & Recursos financeiros & \\
\hline & Outros & \\
\hline \multirow{3}{*}{ Desafios } & $\begin{array}{l}\text { Diversificação das meto- } \\
\text { dologias de aprendizagem }\end{array}$ & \multirow{3}{*}{$\begin{array}{l}\text { Demajorovic (2003); Arevalo et al. } \\
\text { (2011); Baporikar (2014); Canto de } \\
\text { Loura (2014); Ahern (2015); Ryan } \\
\text { et al. (2015) }\end{array}$} \\
\hline & $\begin{array}{l}\text { Mensuração da efetividade } \\
\text { na estratégia }\end{array}$ & \\
\hline & $\begin{array}{l}\text { Resultados obtidos x es- } \\
\text { perados }\end{array}$ & \\
\hline
\end{tabular}

Fonte: Elaborado pelos autores 


\section{RESULTADOS E DISCUSSÃO}

$\mathrm{Na}$ dimensão organizacional apurou-se que 12 das 16 UC estão consolidadas, três estão em processo de formação e uma está como departamento de T\&D, mas com intenções de evoluir para UC. Das que já estão formalizadas, duas não adotaram a nomenclatura de Universidade Corporativa, e sim Educação Corporativa por entenderem ser o termo mais abrangente; 14 delas foram fundadas após o ano 2000 , seguindo uma tendência mundial desta época, e estão distribuídas ao longo destes 18 anos, uma teve início em 1997, em decorrência da estratégia da matriz internacional, que já promovia educação corporativa desde a década de 60 e outra ainda não informou previsão de início. Quanto ao histórico, 14 UCs tiveram sua origem nos departamentos de T\&D das organizações e se consideram como uma evolução natural, um amadurecimento da área.

A gente fala que treinamento já está no nosso DNA, que por ser uma empresa que não encontra mão-de-obra especializada no mercado, ela teve que desenvolver internamente... E em 2008 a gente mudou o modelo, entendendo que, além de treinar a gente precisava olhar para o futuro desenvolver competências mais críticas, o que seria crítico para a gente desenvolver a sustentabilidade do negócio, para a gente se manter atuante no setor e garantir essas competências internamente, e ai a gente começou a mudar o modelo, a gente teve que ficar mais próximo do planejamento estratégico (Empresa 2).

Já existia a parte de T\&D, e teve uma demanda, tinha um apelo interno para a empresa dar novos passos nesse sentido para evoluir junto com o mercado, de ter uma nova postura de atender as estratégias traçadas... acho que foi um combinado da necessidade de evoluir, inovar e de atender uma demanda que já surgia nos bastidores da organização (Empresa 10).

Uma delas já surgiu como UC e outra ainda não está estabelecida. Isto valida a literatura pesquisada, que certifica o surgimento da UC como evolução do T\&D, quando suas ações passaram a ser proativas, de alcan- 
ce estratégico, utilizando várias tecnologias e atuando em todos os níveis hierárquicos para abranger a cadeia produtiva (PRINCE; BEAVER, 2001; EBOLI, 2004; CARBONE, 2013; SENGUR; ACAR, 2014).

O número de funcionários diretos em cada UC difere muito, com a variação de 2 pessoas até 1200 , pois algumas têm equipe fixa apenas para gestão, contam com profissionais que ficam em unidades fora da matriz e que muitas vezes estão alocados em outras áreas, ou seja, trabalham em alguma área relacionada à $\mathrm{RH}$, incluindo nas atividades do cargo, atuar na Educação Corporativa, mas não como atividade única ou principal. Já outras contam com equipe muito grande pois atendem com funcionários próprios da UC, todas as unidades da empresa. Nestes números, não estão incluídos facilitadores eventuais, que normalmente são os próprios funcionários das empresas.

Temos 31 no administrativo, e 930 facilitadores, $85 \%$ são funcionários e $15 \%$ são profissionais contratados, mais para soft skills que a gente contrata ou quando é um tema muito especifico, como legislação, alguma coisa assim, que tem um profissional no mercado que a gente não detenha o conhecimento, mas é difícil, normalmente a gente tem em casa (Empresa 6).

Eu e mais 3 pessoas que ficamos aqui na sede e cuidamos de perto dos executivos e estratégia, e ai a gente tem nas unidades todas as estruturas inclusive a parte de RH que incorpora a educação e treinamento mais operacional, depende da unidade uma estrutura maior ou uma estrutura menor e ai eles fazem qualquer ação de treinamento da unidade (Empresa 8).

Quanto aos cargos dos entrevistados, as nomenclaturas e posições hierárquicas são diversas, há organizações cujos analistas são responsáveis pela gestão da UC e estão subordinados diretamente às diretorias de RH. Em outras tem gerentes executivos que respondem ao CEO ou à vice-presidentes e também aos coordenadores que respondem diretamente às diretorias de RH. Vale destacar que todos os entrevistados têm, independente do título do cargo, autonomia para executar a gestão da UC, seja para a 
tomada de decisões, seja para propor soluções. A idade destes profissionais concentra-se na faixa etária de 30 a 43 anos (70\%). Em relação a formação, predomina o curso de Administração de Empresas: nove profissionais têm formação em Administração, três em Psicologia, um em ambas anteriores, um em Filosofia, um em História e Geografia e um em Comunicação. Do total, 15 gestores já realizaram cursos de pós-graduação ou MBA relacionados à Gestão de Pessoas, Gestão de Negócios ou Educação Corporativa, sendo que apenas um deles tem somente a graduação em Administração. Com formação acadêmica em nível strictu senso, apenas um dos 15 tem mestrado em RH e doutorado em Educação.

Com relação a governança, ou seja, posição hierárquica da UC, 11 respondem à diretoria de $\mathrm{RH}$, dois à Vice-Presidência de $\mathrm{RH}$ e três respondem diretamente ao CEO. Segundo Meister, (1999), Eboli, (2004), Castro e Eboli, (2013) e Baporikar, (2014), uma UC deve estar hierarquicamente ligada à alta administração a fim de facilitar o conhecimento da estratégia e com isso definir quais são as necessidades educacionais para viabilizar estratégia e fortalecer a cultura organizacional.

As estruturas utilizadas nas soluções de aprendizagem são: presencial, virtual ou mista. Para 13 UCs, as ações de aprendizagem acontecem mais de forma presencial do que virtual, em um percentual, na maioria das vezes, acima de $70 \%$ na forma presencial (inclusive em empresas que possuem muitos funcionários); praticamente $30 \%$ de forma virtual e pouquíssimo de forma mista. Apenas três UC declaram ter a maioria de suas soluções de aprendizagem disponíveis prioritariamente de forma virtual. Constatou-se em alguns casos, que apesar da oferta de soluções de aprendizagem presenciais serem maiores em números, a quantidade de acessos nas soluções virtuais supera as presenciais, ou seja, mais funcionários fazem o mesmo curso virtual do que o mesmo curso presencial.

Em geral, eu diria que $75 \%$ é presencial e $25 \%$ são os treinamentos a distância...o panorama do e-learning ele veio para ficar, ele não é um futuro, ele já é presente, agora as grandes empresas têm uma questão de massa crítica, e como as empresas são multilocalizadas, não têm outra alternativa 
que não fazer treinamento online... mas a grande discussão para mim é o impacto que tudo isso vai ter no dia-a-dia do cidadão, o canal a gente precisa aprender tanto no e-lerning quanto no presencial, porque a gente tem a ilusão que a gente aprende, mas tem muita gente que está no treinamento e com a cabeça nas nuvens (Empresa 6).

Acho que a tendência é crescer, até corrigindo, acho que hoje aqui estamos com $60 \%$ presencial e $40 \%$ online, e eu acho que e-learning vai aumentar mais, mas nunca será $100 \%$, sempre terá um pedaço presencial que é fundamental, acho que eles não são concorrentes, são complementares (Empresa 8).

Há tendência para maior uso de soluções virtuais, devido a abrangência, velocidade, custo menor e autonomia para os colaboradores escolherem o tempo e local de aprendizagem (ALLEN, 2002; ABEL; LI, 2012), porém, as soluções presenciais ainda são as mais utilizadas e preferidas (70\%), existindo aqui um desafio de mudança de mentalidade dos colaboradores, de desenvolvimento da cultura do autodesenvolvimento, por meio da aprendizagem virtual (MOSCARDINI; KLEIN, 2015); RYAN et al., 2015); EBOLI, 2016).

O público-alvo privilegiado, prioritariamente, é o interno, os colaboradores, para as 16 UC. Dentre estas, nove desenvolvem também programas para franqueados e revendedores, tendo como foco os negócios, como também desenvolvem algumas soluções para a comunidade, principalmente, ajudando jovens carentes na preparação para o mercado de trabalho, desempenhando assim um papel social. Em alguns casos, também ofertam cursos virtuais para população em geral, dos mais variados temas, disponibilizados em seus websites.

Colaboradores de todos os níveis hierárquicos, temos a divisão de 4 escolas, a de excelência operacional, de liderança, de negócios e de desenvolvimento e inovação, e todas elas têm suas trilhas que são indicadas e também cursos livres. Além disso, capacitamos também nossos fornecedores e franqueados com competências essenciais ao negócio, e ainda temos o braço social, capacitando jovens para o mercado (Empresa 9). 
Abordando a participação da liderança nas soluções de aprendizagem conforme propõe Kolo et al. (2013), Eboli (2016) e Tsipes et al. (2016), todas as UCs declaram que as lideranças têm forte envolvimento, como professores, instrutores, desenvolvedores de conteúdo, realizando a transferência de conhecimento acumulado, tanto de forma explícita como de forma tácita, sendo essas ações consideradas importantes vetores de propagação e manutenção da cultura organizacional.

A gente tem muito conhecimento dentro da empresa, principalmente dentro das fabricas isso é muito forte, o conhecimento está nos próprios colaboradores, isso acontece de maneira bem disseminada ... está falando do número 1 daquela área da indústria, e ele vem aqui no corporativo para ministrar o treinamento sobre o negócio da empresa, então existe sim, e com os cursos online não é diferente, a gente tem cerca de 70 cursos online...e 26 são dos próprios colaboradores (Empresa 8).

Quando questionados sobre a relevância da Sustentabilidade na organização, 14 entrevistados declaram que o tema é altamente relevante e relacionado à estratégia organizacional. Contudo, a Sustentabilidade teve várias interpretações, de acordo com o interesse de cada organização. Este fato é fundamentado por autores como Esteves (2009), Engert et al., (2015), Antonelli et al., (2013) e Parente e Fischer (2014), que afirmam não existir ainda um consenso, uma definição única do que vem a ser Sustentabilidade e que cada organização pode entender e aplicar conceitos de Sustentabilidade, de acordo com o interesse ou necessidade para o negócio. As respostas foram bastante variadas e genéricas, relacionando Sustentabilidade com Tripple Botton Line, sustentabilidade financeira, ética e cidadania e perpetuidade do negócio.

O propósito da empresa, vai além da própria missão, que é construir um mundo melhor de trabalho, fica implícito a questão da sustentabilidade. Tanto nos pilares econômico, social e de meio-ambiente, então tudo que a gente faz, as práticas que a gente tem aqui estão alinhadas nestes 3 pilares, que o conceito de sustentabilidade (Empresa 6). 
A sustentabilidade é muito intrínseca para o negócio da empresa, porque basicamente a maior parte do faturamento vem do agronegócio e os produtos que a gente comercializa são seguem a tendência de saúde animal, que é a questão de poluir menos, de contribuir para o bem estar animal, que é uma lei aqui e mundial, mas projetos paralelos, como reciclagem e etc., não temos (Empresa 14).

Edwards (2009) e Gao e Bansal (2013) argumentam que o entendimento da sustentabilidade merece uma compreensão mais profunda, pois seria requisito para levar a organização a considerar a Sustentabilidade como um valor possível de ser incorporado na estratégia e traduzido em ações de aprendizagem que visem a adequação de seus produtos e/ ou serviços, de forma a transcender o modelo macroeconômico vigente no mundo.

Colocar junto com pessoas e tecnologia promovendo a inovação, que é o core da organização, o pilar da sustentabilidade é neste sentido, seja perpetuidade, garantindo aos funcionários e suas famílias emprego digno e bem como a comunidade uma inserção social (Empresa 16).

Sobre a presença do tema sustentabilidade nos currículos dos cursos e conteúdos oferecidos, 12 das UCs afirmam que o tema está presente de alguma maneira, na maioria das vezes no formato de cursos prontos adquiridos no mercado, também chamados de cursos de prateleira. Para Hart (2006) e Edwards (2009), a sustentabilidade só integrará a cultura organizacional quando, por meio de conteúdos e ações educacionais, todos os funcionários aprenderem, entenderem e incorporarem o conceito de Sustentabilidade, de forma a modificar seus valores e suas práticas pessoais e organizacionais.

Importante notar que quatro entrevistados declaram ter pouca ou nenhuma abordagem do tema sustentabilidade em suas soluções de aprendizagem, o que pode ser considerado como um contrassenso, pois somente um destes quatro não reconhece a Sustentabilidade como fator relevante para a organização. 
Fiz um benchmarketing recente com outras UCs tem essa frente desenvolvida, acho que é a frente mais difícil de desenvolver é ligada a sustentabilidade, as vezes jogam 2, 3 conteúdos de prateleira, que honestamente a grosso modo foi o que a gente fez também, tem muito conteúdo de commodite, dentro de uma plataforma aberta, isso ajuda, mas não mexe no ponteiro de um pequeno negócio (Empresa 15).

Eu não consigo enxergar alguns pilares de sustentabilidade ainda nos nossos cursos, eu acho que é um pouquinho cru ainda (Empresa 7).

Falando propriamente dos programas de sustentabilidade, a empresa tem uma capacitação do próprio time de sustentabilidade que eles vão até as áreas e ficam fazendo rodadas de sustentabilidade, então hoje são duas pessoas focadas nisso, que eles rodam as unidades e fazem worksohp com os colaboradores para debater sustentabilidade. Eles tem uma outra ação que é, eles lançaram como fosse um cartoon, um livrinho de histórias com depoimento dos colaboradores, contado situações reais dentro ou fora da empresa, que a sustentabilidade na vida deles, um ex. um colaborador aqui vem de bicicleta todos os dias, como é o impacto disso, o outro gosta de planta, mas a UC não interfere em nada neste trabalho (Empresa 8).

Outros quatro declaram que os cursos com essa temática são desenvolvidos pelo departamento de sustentabilidade com pouco ou nenhum envolvimento da UC, o que demonstra o pouco entendimento dos profissionais das UCs em relação à sustentabilidade, o que pode influenciar indiretamente a baixa quantidade de abordagens específicas da Sustentabilidade por parte das UCs.

A área de sustentabilidade tem ações mais pontuais, é uma área que está super bem estruturada, tem temas relevantes que eles trabalham, porém a UC ainda não teve uma proximidade, acho que a gente nunca conversou sobre isso, a gente nunca se preocupou, a gente ainda tem muita coisa para introduzir, para atender uma grade que a empresa espera desta UC, talvez depois a gente consiga pensar nestas outras questões (Empresa 4).

Nenhuma UC participante menciona abranger ao mesmo tempo conteúdos de sustentabilidade relacionando todos seus aspectos - econôm- 
icos, ambientais, sociais e até mesmo culturais - em suas soluções de aprendizagem. Quando alguma diz que está presente de forma transversal, não consegue esclarecer como isso é feito efetivamente. Quando presentes, estes conteúdos aparecem de forma fragmentada, atendendo problemáticas específicas e pontuais, como legislações e por vezes misturados com outros temas, como ética e diversidade.

Temos o desafio de ter a sustentabilidade de forma transversal em todos os cursos, visando a promoção e prática de ações sustentáveis, principalmente nos cursos para gestores. Temos também cursos específicos de sustentabilidade, em torno de 9 cursos, que tratam de temas socioambientais, mas também temos outros cursos temas relacionados com sustentabilidade, como ética e corrupção, direitos humanos, diversidade. São cursos na sua grande maioria online (Empresa 1).

Hoje somos certificados pela ISO 14000, pelo selo tem vários conteúdos relativos ao meio ambiente que são obrigatórios, ex. nosso SGA, até pouco tempo era obrigatório para todo mundo, agora a gente já tá saindo deste nível e tratando só quem entra na empresa, para entender um pouco este tema, então a gente não tem o conteúdo sobre o que é sustentabilidade, mas tem vários conteúdos que estão relacionados com a sustentabilidade (Empresa 2).

Esta fragmentação pode comprometer o entendimento do que vem a ser Sustentabilidade. E se o tema não é entendido em sua totalidade, o ensino da Sustentabilidade pode ficar incompleto, inconsistente e também comprometer o atendimento à estratégia organizacional. Isto reforça a afirmação de Demajorovic (2003) de que uma mudança organizacional em relação aos aspectos socioambientais está fortemente relacionada a um novo processo de formação dos profissionais das organizações, não resolvendo apenas colocar a variável socioambiental na estratégia, mas ao considerar uma nova forma de aprender, mais abrangente.

Com referência ao acesso ao conteúdo de sustentabilidade, não há nenhuma restrição, de forma que na maioria das UCs estes conteúdos estão disponíveis a todos os funcionários, independentemente do nível 
hierárquico. Para os gestores, segundo 12 entrevistados, a participação nos cursos da UC é obrigatória, sendo parte da formação completa para o cargo, junto com temas como desenvolvimento de negócios, gestão de pessoas. No entanto, um dos problemas relatados pelas organizações para incluir todos os colaboradores nos processos de aprendizagem das UCs é a falta de infraestrutura adequada, uma vez que localidades distantes de grandes centros contam com internet precária, impossibilitando a organização de se beneficiar dos processos de ensino à distância, visto que nestes casos os conteúdos são virtuais por necessidade, e não por considerar a ferramenta relevante.

Sim, todos os níveis têm acesso, e como está na estratégia da empresa todos tem acesso, mas não são obrigatórios para todos os cargos, depende da trilha de aprendizagem traçada. Mas se for considerar o tema ética, todos os funcionários têm que fazer, e renovar este curso anualmente, via portal (Empresa 1).

Recentemente estava com um programa que a ideia e disseminar os pilares e a política da sustentabilidade em todas as unidades, que são 3 itens, ai sim será um treinamento formal sobre isso, a ideia e fazer um treinamento online, como nosso portal é muito forte, a gente quer chegar a um maior número de colaboradores, a gente entendeu que o canal mais interessante é mais o online do que o presencial, pois esse demoraria muito tempo (Empresa 8).

Quanto às barreiras levantadas na literatura, Coleman (2013) e Blake (2016), ressaltam que a resistência ao tema ainda existe em todos os níveis das organizações, principalmente nos níveis estratégicos, devido ao modelo de gestão operante, que ainda valoriza o fator econômico em detrimento dos fatores socioambientais. Para que a Sustentabilidade seja incorporada nas organizações, é necessária uma mudança de modelo de gestão macro e microeconômico. No entanto, 15 UCs relataram não existir resistência, mas sim desconhecimento ao tema, ou quando conhecido, ser entendido de forma superficial, o que dificulta sua aplicação no planejamento e nas práticas do dia-a-dia, contribuindo para um descompasso entre discurso e prática. 
Eu acho o que existe aí e me incluiu nisso é a falta de conhecimento. O que é, o que faz, de onde veio, onde vive, e que seja um pouco mais vivo. Como a equipe de sustentabilidade ficará mais robusta eu acho que vai deixar esse limbo que existe um pouco mais claro, não sei se a palavra é resistência, existe algo que é natural e pode ter a responsabilidade da área, o problema de RH é de RH e o problema de sustentabilidade é do departamento de sustentabilidade (Empresa 11).

Eu acho que tinha uma certa necessidade de entender e se posicionar. O que é sustentabilidade nesta empresa? O que significa isso? Aonde ela pode atuar de forma sustentável, apesar de todo programa de sustentabilidade, eu sentia que as pessoas queriam entender mais sobre isso. Eu não via resistência não, pelo contrário, as pessoas queriam saber mais (Empresa 12).

Um entrevistado, declara não haver em sua organização nenhuma resistência à sustentabilidade, sendo ela o principal valor adotado pelo proprietário (hoje presidente) da organização. A sustentabilidade é vivenciada integralmente, sendo abordada nas entrevistas de contratação, reforçada na integração e vivenciada nas ações do dia-a-dia, por meio da valorização e estímulo à participação em ações voluntárias promovidas pela organização.

Aqui já temos a cultura da sustentabilidade, desde nosso presidente, que é o dono... é que já está tanto no sangue nosso isso; acho que para as novas pessoas que estão entrando é um desafio, então precisamos acultura-las no nosso ambiente de sustentabilidade..., então acho que o nosso maior desafio é contratar bem pessoas, mas também acultura-las no nosso jeito de SER (Empresa 5).

Este caso reforça os argumentos de Ahern (2015) e Blake (2016) que destacam a relevância da aprendizagem da sustentabilidade para a liderança, pois é a partir deste nível hierárquico que a disseminação acontecerá de forma efetiva para todos os níveis organizacionais. A mudança no estilo de gestão vem a partir da presidência (dono) e acionistas, com a promoção do conhecimento e conscientização da liderança, diálogos sistêmicos, disseminação da missão e valores alinhados à sustentabilidade para todos os 
colaboradores, desenvolvimento contínuo destes, culminando na inovação dos produtos e da gestão (ROOME; LOUCHE, 2011); RAGUSA, 2011).

Para fortalecer a competência da liderança, que é um gap da maioria das organizações, a gente percebeu que havia uma dificuldade do entendimento do que é sustentabilidade, o que a empresa queria dizer com liderança, a gente desenvolveu as 5 práticas do líder, e dentro dessas 5 práticas, uma delas é um compromisso com a sociedade, então agir com integridade, com ética, ou seja, agir com princípios da sustentabilidade (Empresa 16).

Outra barreira é a existência ou não de uma cultura que privilegie a sustentabilidade. A importância da disseminação de uma cultura da Sustentabilidade é fundamental para que esta seja traduzida para o gerenciamento e ações, conforme defendido por Hart (2006), Edwards (2009), Gao e Bansal (2013), Ahern (2015) e Blake (2016). Para Oncica-Sanislav e Candea (2010) para uma organização ter a sustentabilidade incorporada em sua cultura, precisa ter visão compartilhada de seus valores por toda a organização, como consequência, a liderança traçará objetivos de longo prazo que tragam benefícios econômicos, sociais e ambientais. Quatro UC declaram que a sustentabilidade já faz parte da cultura, outras três declaram que a sustentabilidade começa a fazer parte da cultura, com influência ainda limitada nos momentos de decisão estratégicos. Para as outras nove UCs, mesmo que a sustentabilidade esteja presente declaradamente na missão, visão e valores, ainda não está presente na cultura, o que faz prevalecer o fator econômico nos momentos de decisões estratégicas e definições de direcionamento tanto das organizações como das UCs.

Já faz parte da cultura da empresa, e também da estratégia (Empresa 1).

Entendemos que as pessoas já reconhecem, mas ainda não está no DNA. É uma jornada e estamos atuando para transformar o tema em algo natural (Empresa 15). 
É economicamente viável ser sustentável, que quando tem um foco no econômico, no social e no ambiental, cria uma imagem positiva para a organização...mas o processo é lento, a empresa hoje precisa sobreviver, precisa de novos negócios, se é sustentável ou não, não interessa, é preciso novos negócios, mas na medida que as pessoas vão se conscientizando, vão se aproximando vai mudando (Empresa 3).

Quanto aos desafios, um está relacionado a encontrar, desenvolver e até mesmo aplicar novas metodologias de aprendizagem. Novamente as respostas foram genéricas, relacionadas a várias temáticas e não especificamente à Sustentabilidade. O desafio maior apontado, independente do tema, é o fato de que as pessoas aprendem de formas diferentes, portanto necessitam de diversas metodologias para o mesmo tema, visando atender individualmente cada colaborador. Arevalo et al. (2011) aponta que ainda não se tem estudos empíricos suficientes que comprovem que metodologias experienciais são mais efetivas do que metodologia formal e tradicional, ou vice-versa.

Eu acho que é uma coisa que a gente tenta buscar sempre, a gente está muito atento a isso, o tempo inteiro, acho que a gente tenta se atualizar, no mundo atual não dá para ficar parado e acho que é muito legal e cada pessoa aprende de um jeito, então possibilitar isso, e buscar os diferentes canais...e o importante é não fazer por modismo mas quando percebe que tem m sentido fazer aquilo. Por ex., a questão do celular, a gente tem hoje muita coisa no celular, e não é porque é moda, mas está comprovado e nosso público usa e a gente tem o aplicativo (Empresa 8).

A diversificação de metodologias é uma necessidade. As pessoas não aprendem mais como antigamente em longos cursos, eles devem estar conectados com a prática, fazer sentido a todo momento. Aí sim se torna um belo desafio (Empresa 15).

Apenas uma UC se refere à metodologia específica para o ensino da Sustentabilidade e aposta no diálogo livre e aberto, no qual as pessoas possam falar e pensar, num processo de construção de conhecimento. 
Eu diria o seguinte, primeiro abrir espaço para o diálogo sobre isso, falo de diálogo aberto, não e apresentação, é diálogo, é colocar grupos de pessoas de diversa áreas, dá trabalho? Dá, mas é uma das formas mais efetivas de se fazer isso, trazer o assunto para as pessoas falarem e pensarem o que significa sustentabilidade para mim e o significado para a empresa na qual eu trabalho, o que é importante que eu acho para a gente e você faz um processo de construção de conhecimento, com diálogos diversos, preparar pessoas adequadas que conduzam esse diálogo que não sejam os condutores do diálogo, mas os facilitadores de diálogo (Empresa 12).

Pless et al. (2012) aponta que programas para as lideranças, realizados por meio de missões internacionais de aprendizado e serviços em locais com poucos recursos naturais, sociedades carentes e infraestrutura mínima, podem estimular a conscientização da relação da sustentabilidade com as decisões estratégicas e mesmo contribuir para a maior consciência dos desafios globais. Duas UCs declaram que seus executivos têm treinamentos e formações fora do Brasil, não por meio de missões, mas sim em UTs ou nas UCs da própria organização. Como vantagem afirmam o maior avanço das questões referentes à sustentabilidade tanto em UCs quanto UTs fora do país. 


\section{CONSIDERAÇÕES FINAIS}

Esta pesquisa teve como objetivo verificar como UCs promovem a educação para a sustentabilidade nos seus diversos níveis organizacionais no cenário atual. Se por um lado, a UC é tida como responsável pela promoção e preparação do capital humano para o alcance das estratégias organizacionais, e por outro, a sustentabilidade é considerada como um dos elementos centrais destas mesmas estratégias organizacionais, espera-se que haja diálogo de modelos e de ações conjuntas, que envolvam essas duas áreas das organizações. Entretanto, os resultados mostram um grande distanciamento entre elas que parece inviabilizar uma conexão adequada, indicando que essas duas áreas caminham de forma paralela, ou seja, praticamente não se encontram ou interagem.

Embora as UCs relatem que tenham conteúdos específicos de sustentabilidade e metodologias diferenciadas como componentes de suas práticas educativas, nenhuma delas declarou ter algum plano de educação que indicasse a atuação específica voltada para o compromisso com a sustentabilidade. As ações ou metodologias equivalentes das UCs não servem como base para a elaboração de algum modelo teórico-empírico para o ensino e aprendizagem da sustentabilidade, uma vez que cada UC tende a customizar seu próprio modelo.

Outro resultado relevante é que não existe resistência, mas sim um desconhecimento do que significa sustentabilidade, de como ela pode ser relacionada à estratégia organizacional e ainda de como ela pode ser traduzida em ações do cotidiano da organização, ou seja, como a sustentabilidade pode fazer parte da cultura. Este fato reforça a importância da educação para a sustentabilidade em todos os níveis hierárquicos, no sentido de disseminar o conhecimento e possibilitar sua inclusão na cultura e nas práticas organizacionais. Os gestores consideram como principal desafio para a UC, em relação a educação para a sustentabilidade, a ausência de diálogo entre as UCs e os departamentos de sustentabilidade. O conhecimento e as ações de sustentabilidade estão concentrados em seus departamentos específicos e as UCs por sua vez, ainda não assumiram seu papel na disseminação des- 
ses conhecimentos. Assim, os conhecimentos sobre sustentabilidade encontram-se muitas vezes restrito aos profissionais e aos departamentos específicos das organizações. Estes departamentos têm por responsabilidades as ações relacionadas à gestão da sustentabilidade em si, como por exemplo o atendimento à legislação específica, aos controles de riscos ambientais, às ações sociais, à elaboração dos relatórios anuais de sustentabilidade. Além disso, os departamentos de sustentabilidade também são os responsáveis pelas ações educacionais que promovam a educação da sustentabilidade internamente nas organizações e, por vezes, junto aos outros stakeholders, o que deixa a UC à margem dessas ações educacionais. Dessa forma, este aprendizado acaba sendo fragmentado e pontual pois não está diretamente relacionado à estratégia.

Infere-se então, que a sustentabilidade não faz parte das ações das UCs, há pouco conhecimento do tema por parte dos profissionais das UCs, o que pode justificar o baixo interesse nesta temática e as poucas ações encontradas. Pode-se constatar que o diálogo entre a UC e o departamento de Sustentabilidade é praticamente nulo. Um fato que se destaca nesta pesquisa é que uma das UCs participantes está subordinada à mesma diretoria que o departamento de Sustentabilidade e mesmo assim, o diálogo e ações envolvendo ambos, até o momento, é inexistente. Além disso, reforça também a importância do ambiente externo para estimular as empresas a incorporar a sustentabilidade, como observado em outros países, levando a um maior envolvimento das UCs nesta temática.

Os resultados obtidos contradizem o pressuposto desta pesquisa, de que UC e educação para sustentabilidade podem conjuntamente contribuir para reforçar o desempenho das organizações nos campos econômicos, social e ambiental e os poucos estudos relacionando ambos os temas, também não encontraram respaldo nas organizações estudadas e não há elementos que identificados poderiam alterar esta realidade num futuro próximo.

Outras questões podem ser levantadas para avançar nessa discussão, como por exemplo: seria mesmo a sustentabilidade relevante e significativa para as organizações a ponto de estar presente e influenciar suas estratégias 
organizacionais? O entendimento da sustentabilidade por parte da alta administração interfere de alguma forma na priorização dessa, com relação as soluções de ensino e aprendizagem? O entendimento da sustentabilidade por parte dos profissionais das UCs pode influenciar positivamente para um novo posicionamento dela em relação à educação para sustentabilidade? Será que alguma metodologia específica pode promover resultados mais efetivos na educação para sustentabilidade, de modo a influenciar positivamente a cultura organizacional e os resultados financeiros?

Questões como essas podem orientar discussões entre os profissionais das Universidades Corporativas e os profissionais de sustentabilidade, promovendo debates na esfera organizacional, no sentido de encontrar novos caminhos a seguir no que se refere a educação para sustentabilidade. São questões relevantes que precisam de um maior número de dados provenientes de pesquisas empíricas, permitindo o avanço do arcabouço teórico e novos insights para a promoção da educação para sustentabilidade nas organizações, por meio das UCs. 


\section{REFERÊNCIAS}

ABEL, A. M.; LI, J. Exploring the Corporate University Phenomenon: development and implementation of a comprehensive survey. Human Resource Development Quarterly, v.23, no 1 , p. 103-126. 2012.

AHERN, G.M. Imagining what underlies corporate sustainability. Journal of Management Development. v. 34, n.4, p.494-504. 2015.

ALAGARAJA, M.; LI, J. Utilizing institucional perpsectives to investigate the emergence, rise, and (relative) decline of corporate universities. Human Resource Development International, v.18, n.1, p.04-23. 2015.

ALLEN, M. Corporate Universities 2010: Globalization and Greater Sophistication. The Journal of Internation Management Studies, v. 5, n.48, p. 48-53. 2010.

The Corporate University Handbook: Designing, Managing, and Growing a successful program. New York: Amacon, 2002.

The Next Generation of Corporate: Innovate approaches for developing people and explanding organizational capabilities. San Francisco: Pfeiffer, 2007.

ALPERSTEDT, C. Universidades corporativas: discussão e proposta de uma definição. Revista de Administração Contemporânea, v. 5, n. 3, p. 149-165, set./ dez. 2001.

ALVARES, K.P.; SOUZA, I.M. Sustentabilidade na gestão de pessoas: práticas e contribuições às organizações. Revista Gestão Organizacional, v.9, n.2, p.24-38. 2016.

ANTONELLI, G.; CAPPIELLO, G.; PEDRINI, G. The Corporate University in the European utility industries. Utilities Policy, v.25, p.33/41. 2013.

AREVALO, J.A.; CASTELLÓ, I.; COLLE, S.; LENSSEN, G.; NEUMANN, K.; ZOLLO, M. Introduction to the special issue: integrating sustainability in business models. Journal of Management Development, v.30, n.10, p.941-954. 2011.

BAPORIKAR, N. Corporate university edification in knowledge society. International Journal Strategic Change Management, v. 5, n. 2, p.125-139. 2014.

BARDIN, L. Análise de Conteúdo. Lisboa, Portugal: Edições 70, LDA., $3^{\text {a Ed., }} 2004$.

BELINKY, A. A terceira geração da sustentabilidade empresarial. GV-executivo, v. 15, n. 2, p. 39-42, jul./ dez. 2016.

BLAKE, P. Management Behavior toward the Integration of Sustainability. SAM Advanced Management Journal. Sumer 2016.

BRANCO, A.R. O Perfil das Universidades Corporativas no Brasil. São Paulo: RAM - Revista de Administração Mackenzie. v.7, n.4, p.99-120. 2006.

BRUNSTEIN, J.; SCARTEZINI, V. Neri; RODRIGUES, A. L. Sustentabilidade na educação corporativa e o desenvolvimento de competências societais. Organizações e Sociedade, v.19, n.63, p. 583-598, out/dez. 2012. 
BRUNSTEIN, J; RODRIGUES, A.L. Gestores e sustentabilidade: a difícil tradução do significado para a ação competente. Revista Alcance, v.21, n.1, p. 5-24, jan/mar. 2014.

CARBONE, P.P. Gestão por competência e educação corporativa: caminhos para o desenvolvimento de competências. Inclusão Social, v.7, n.1, p.44-55, jul./ dez. 2013.

CARMELLO, E. Cinco metodologias inovadoras da aprendizagem. Revista T\&D Inteligência Corporativa. v.191, p.42-50. 2015.

CASTRO, C. M.; EBOLI, M. Universidade Corporativa: Gênese e questões críticas rumo à maturidade. São Paulo: RAE Revista de Administração de Empresas, v.53, n.4, p. 408 -414 , jul-ago. 2013.

COLEMAN, G., Sustainability as a learning challenge, Journal of Management Development, v.32, n.3, p. 258-267. 2013.

CONTE, A.; RAMOS, F.; JANUARIO, S. Universidade Corporativa: uma nova "roupagem" para a área de Treinamento e desenvolvimento? RPCA - Revista Pensamento Contemporâneo em Administração, v.5, n.1, p.56-65, jan/abr. 2011. DOI: http:// dx.doi. org/10.12712/rpca.v5i1.20

CREWS, D. E. Strategies for implementing sustainability: five leadership challenges. SAM Advanced Management Journal, v.75, n.2, p.15-21. 2010.

DEMAJOROVIC, J. Sociedade de risco e responsabilidade social, perspectivas para a educação corporativa. São Paulo: Ed. Senac, 2003.

EDWARDS, M.G. An integrative metatheory for organization learning and sustainability in turbulent times. The learning organization, v.16, n. 3, p. 189-207. 2009.

EBOLI, M. Desenvolvimento e alinhamento dos talentos humanos às estratégias empresariais: o surgimento das universidades corporativas. São Paulo: Schmukles Editores, 1999.

2004.

Educação Corporativa no Brasil: mitos e verdades. São Paulo: Editora Gente,

Papéis e responsabilidades na gestão da educação corporativa. In: EBOLI, M.

et al. (Orgs). Educação Corporativa: fundamentos, evolução e implantação de projetos. São Paulo: Atlas, 2010.

Educação Corporativa nos novos cenários empresariais. GV-executivo, v. 15, n. 2, p.20-24, dez. 2016.

EDWARDS, M. G. An integrative metatheory for organization learning and sustainability in turbulent times. The Learning Organization, v. 16, n. 3, p. 189-207. 2009.

ENGERT, S.; RAUTER, R.; BAUMGARTNER R. J. Exploring the integration of corporate sustainability into strategic management: a literature review. Journal of Cleaner Production, v.112, n.4, p. 2833-2850. 2015. 
GAO, J.; BANSAL, P. Instrumental and integrative logics in business sustainability. Journal of Business Ethics, v.112, p. 241-255. 2013.

HART, S. L.; MILSTEIN, M. B. Creating sustainable value. Academy of Management Executive, v.17, n.2, p. 56-67. 2003.

HART, S. L. O capitalismo na encruzilhada: as inúmeras oportunidades de negócios na solução dos problemas mais difíceis do mundo. Porto Alegre: Bookman. 2006.

HOMAN, G.; MACPHERSON, A. E-learning in corporate university. Journal of Europen Industrial Training. v.29, n.1, p.75-90. 2005.

HUBBARD, G. Measuring organizational performance: Beyond the triple bottom line. Business Strategy and the Environment, v.19, p. 177-191. 2009.

KOLO, P.; STRACK, R.; CAVAT P.; TORRES, R; BHALLA, V. Corporate Universities: an engine for human capital. BCG The Boston Consulting Group. 2013.

MARGHERITA, A.; SECUNDO, G. Networked Learning for Human Capital Development. In: ROMANO, A. Open Business Innovation Leadership: the emergence of the stakeholder university. London: Palgrave, 2009. Cap.3, pp.70-108.

MCATEER, P.; PINO, M. The business case for creating a corporate university. New York, NY: Corporate University Xchange, 2011.

MEISTER, J. C. Educação corporativa: a gestão do capital intelectual através das universidades corporativas. São Paulo: Makron Books, 1999.

MERRIAM, S. B. Qualitative Research and Case Study Applications in Education. Revised and Expanded from "Case Study Research in Education". San Francisco: JosseyBass Publishers, 1998.

MOSCARDINI, T.N.; KLEIN, A. Educação corporativa e desenvolvimento de lideranças em empresas multisite. RAC - Revista de Administração Contemporânea, v.19, n.1, p. 84-106. 2015.

ONCICA-SANISLAV, D.; CANDEA, D. The learning organization: a strategic dimension of the sustainable enterprise. In: Proceedings of the $6^{\text {a }}$ European Conference of Management, Leadership \& Governance, pp. 263-270. 2010.

PARENTE, T. C.; FISCHER, A.L. A relação entre recursos humanos e sustentabilidade como tema emergente: uma análise bibliométrica. Revista Alcance, v.21, n.3, p.398-421, jul/set. 2014. DOI: 10.2139 / ssrn.1865320.

PLESS, N.M.; MAAK, T.; WALDMAN, D.A. Different approaches toward doing the right thing: Mapping the responsibility orientations of leaders. Academy of Management Perspective, v.26, n.4, p.51-65. 2012.

PORTER, M.; KRAMER, M. Creating shared value: how to reinvent capitalism and unleash a wave of innovation and growth. Harvard Business Review, v.89, n.1, p. 62-77. 2011. 
PRINCE, C.; BEAVER, G. The rise and rise for corporate universities: the emerging corporate learning agenda. International Journal of Management Education, v.1, n.2, p. 17-26. 2001.

RAGUSA, R. Integration of company responsibility, the learning process: the Autogrill case. Journal of Management Development, v. 30, n.10, p. 1000-1016. 2011.

RENAUD-COULON, A. Corporate Universities: a Lever of Corporate Responsibility. Paris: Global CCU, Publishing, 2008.

RHEAUME, L.; GARDONI, M. The challenges facing corporate universities in dealing with open innovation. Journal of Workplace Learning, v. 27, n.4, p.315-328. 2015.

REIS, G.G; SILVA, L.M.T.; EBOLI, M. A Prática reflexiva e suas contribuições para a Educação Corporativa. São Paulo. REGE - Revista de Gestão, v. 17, n. 4, p. 403-419, out./ dez. 2010.

ROOME, N.; LOUCHE, C. Sabaf: moving to a learning environment. Journal of Management Development, v.30, n.10, p.1049 -1066. 2011.

RYAN, L. Exploring the growing of university-corporate education partnerships. Management Decision, v.47, n.8, p.1313-1322. 2009.

RYAN, L.; PRINCE, C.; TURNER P. The changing and developing role of the corporate university post-millennium. Industry \& Higher Education v.29, n.3, p.167-174. 2015. DOI: 10.5367 / ihe.2015.0256.

SENGE, P. M. A quinta disciplina: arte e prática da organização que aprende. 16 ed. São Paulo: Editora Nova Cultural, 2004.

SENGUR, E.D.; ACAR, A.B. Moving from Corporate Training to Corporate Education: a case study in accoutancy from Turkey. In: Adult and Continuing Education: concepts, methodologies, tools and applications, EUA: cap.83, pp. 1457-1474. 2014. DOI: 10.4018/978-1-4666-5780-9.ch083.

SILVA, M.W. Universidade corporativa: uma avaliação no contexto do ensino superior no Brasil. 2005. 135pg. Dissertação (Mestrado em Educação, na área de Ensino Superior do Centro de Ciências Sociais Aplicadas) - Pontifícia Universidade Católica de Campinas, Campinas, 2005.

STACEY, E; GERBIC, F. Effective blended learning practices: evidence-based perspectives in ICT- Facilitade Education. USA: IGI Global, 2009.

TARAPANOFF, K. Panorama da educação Corporativa no Contexto Internacional. In: Educação Corporativa: Contribuição para a competitividade/Organização Secretaria de Tecnologia Industrial. Brasília: Petróleo Brasileiro e CNI, 2004, cap. 1, pp. 11-84.

TSIPES, G; ECHKALOVA, N.; SHAVORAVA, E.; TOVB, A. Corporate University as a driver of project culture and competence development. Procedia - Social and Behavioral Scienses, v. 226, p. 335-342. 2016. 
VERGARA, S; RAMOS, R. Motivos para a criação de universidades corporativas - estudos de caso. RAE - Revista de Administração Mackenzie. Ano 3, n.2, p.79-98. 2002.

WALTON, J. Strategic Human Resource Development. Harlow: Pearson Education. 1999.

WESSELINK, R.; BLOK, V.; VAN LEUR, S.; LANS, T.; DENTONI, D. Individual competencies for managers engaged in corporate sustainable management practices. Journal of Cleaner Production, v.106, p.497-506. 2015.

WILSON, A.; LENSSEN, G.; HIND, P. Leadership qualities and management competencies for corporate responsibility: a research report for the European business in society. UK: European Academy of Business in Society - EABIS, UK, 2006.

ZERBINI, T.; CARVALHO, R.S.; ABBAD, G.S. Evasão em curso via internet: explorando variáveis explicativas. RAE-eletrônica, v. 5, n. 2, Art. 17, jul./ dez. 2006. 


\section{DADOS DOS AUTORES}

\section{MONICA APARECIDA DE SORDI MARTÃO monicadesordi@uol.com.br}

Doutora em Administração - FEI

Instituição de vinculação: Centro Universitário FEI

São Paulo/SP - Brasil

Áreas de interesse em pesquisa: Educação Corporativa; Recursos Humanos; Sustentabilidade.

Rua Justino Paixão, 547, casa 13 Jardim São Caetano São Caetano do Sul/SP 09580-780

\section{JACQUES DEMAJOROVIC jacquesd@fei.edu.br}

Doutor em Educação pela USP

Instituição de vinculação: Centro Universitário FEI

São Paulo/SP - Brasil

Áreas de interesse em pesquisa: Logística reversa, educação e inovação para sustentabilidade, turismo e sustentabilidade e licença social para operar. 